\title{
Endoscopic resection of a pediatric pyogenic granuloma of the major papilla
}

The lobular capillary hemangioma, also known as pyogenic granuloma, is a common benign vascular tumor that generally appears in the skin or oral cavity. Rarely, it may arise in the small intestine and cause refractory bleeding [1]. Resection is the mainstay of treatment as spontaneous regression is uncommon. We report the case of a 13-year-old girl presenting with chronic refractory iron-deficiency anemia. She complained of intermittent weakness over the past 3 years. Previous endoscopy and colonoscopy revealed only an edematous major papilla. Biopsy showed exuberant granulation tissue. At the time of referral to our center, she had already received several intravenous iron infusions and blood transfusions.

We performed a side-viewing endoscopy and found a 15-mm erythematous polypoid lesion in the major papilla ( $\mathbf{F i g} \mathbf{1}$ ). We performed new biopsies, and histopathological results were consistent with the diagnosis of pyogenic granuloma. We decided to proceed with an endoscopic papillectomy. We resected the major papilla using the standard technique, but we kept the snare entirely closed for 5 minutes before applying the electrical current. This technical peculiarity aimed to promote primary hemostasis, thus avoiding later bleeding (> Fig. 2 ,

- Video 1). The procedure was on an inpatient basis.

The patient had an uneventful postprocedural course and was discharged 3 days after the resection. At 6 months, hemoglobin levels and iron profile had returned to normal. She required no further intravenous iron infusion or blood transfusions. The specimen analysis confirmed the diagnosis of lobular capillary hemangioma (pyogenic granuloma) (> Fig.3, - Fig.4).

This is the first report of a pediatric pyogenic granuloma in the major papilla; previous reports have all been in adults [2-5]. Pyogenic granuloma in the major papilla is rare and endoscopic resection

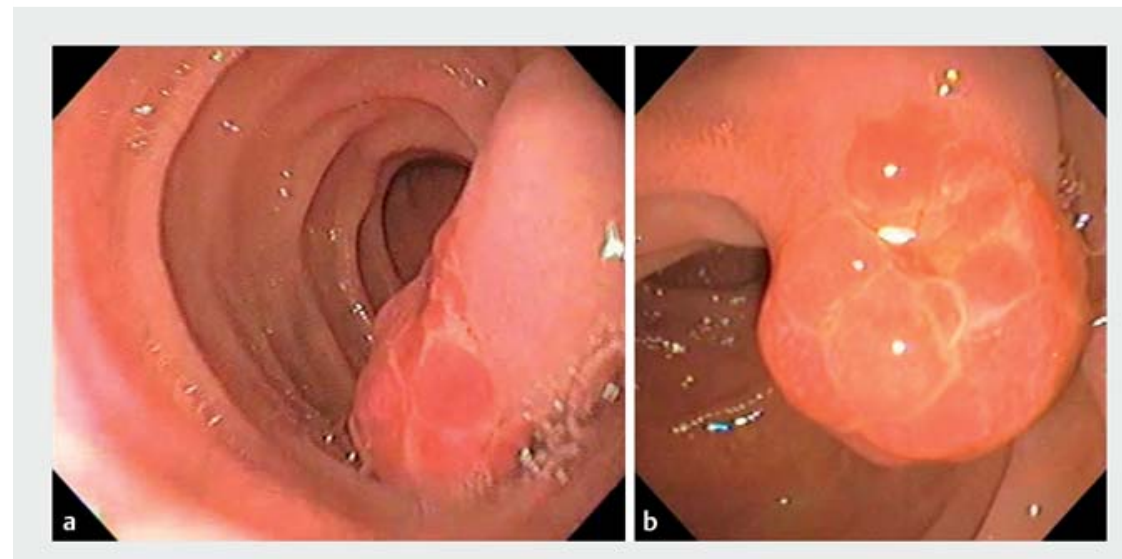

Fig. 1 Endoscopic aspects of the pyogenic granuloma. a, b A 15-mm erythematous polypoid lesion was found in the major papilla.
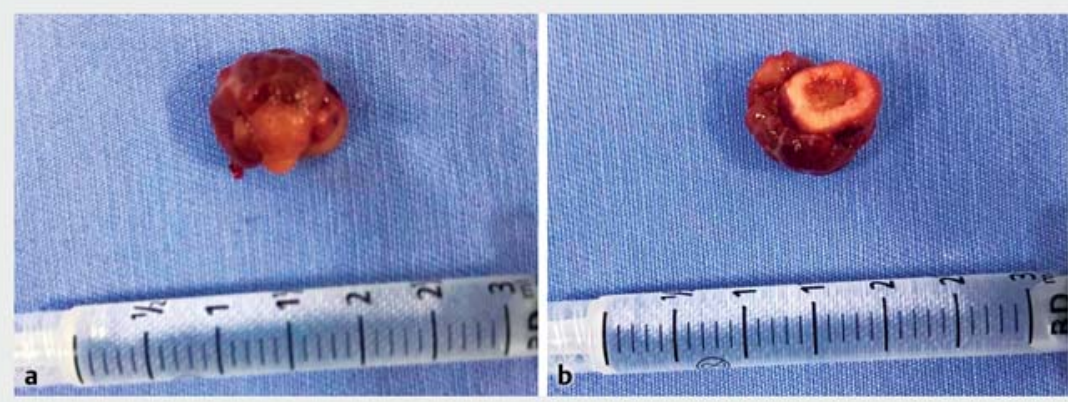

Fig. 2 The resected specimen as a soft polypoid lesion of $20 \times 15 \times 12 \mathrm{~mm}$. a Luminal side of the lesion. $\mathbf{b}$ Resection side of the lesion.
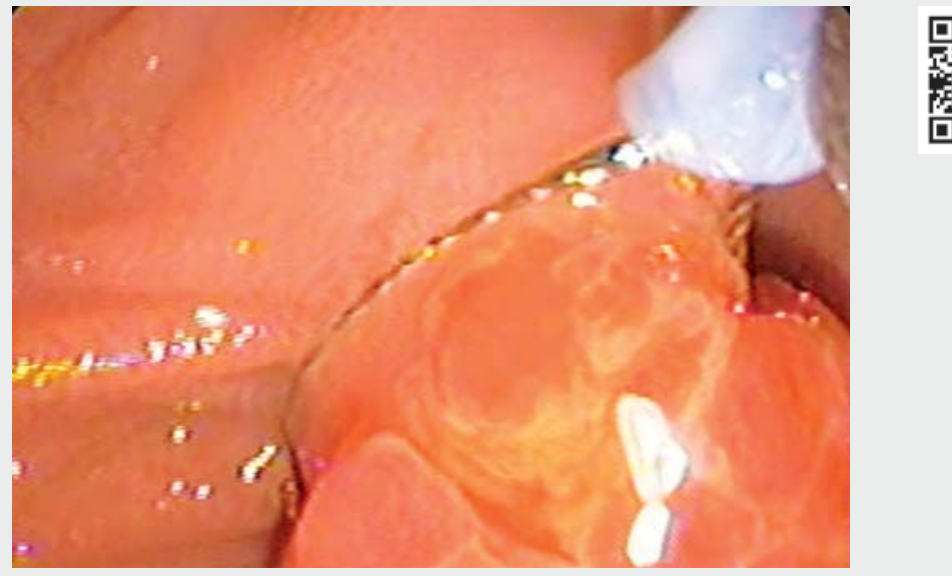

Video 1 Endoscopic resection of a pyogenic granuloma of the major papilla. 


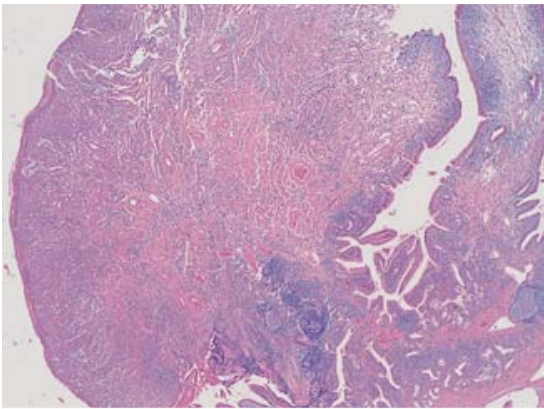

Fig. 3 An ulcerated polypoid lesion in the major papilla mucosa. The lesion exhibited lobular architecture with an exophytic and non-infiltrative growth pattern (hematoxylin and eosin, $\times 20$ ).

is a possible therapeutic alternative even in childhood.

Endoscopy_UCTN_Code_CPL_1AH_2AZ

Competing interests

The authors declare that they have no conflict of interest.

The authors

\section{Ricardo Stefano da Penha ${ }^{1}{ }^{\oplus}$, Jose Eduardo Brunaldi ${ }^{1}$, Gustavo Murad Pinton ${ }^{2}$, Lucas Tobias Almeida Queiroz ${ }^{1}$, Yuri Zamban Vieira ${ }^{1}$, Ligia Magnani Landell Camarero ${ }^{3}$, Vitor Ottoboni Brunaldi ${ }^{1} \odot$ \\ 1 Center for Gastrointestinal Endoscopy, Surgery and Anatomy Department, Faculty of Medicine of Ribeirão Preto, Ribeirão Preto, Brazil}

2 General Surgery Unit, São Francisco Hospital, Ribeirão Preto, São Paulo, Brazil

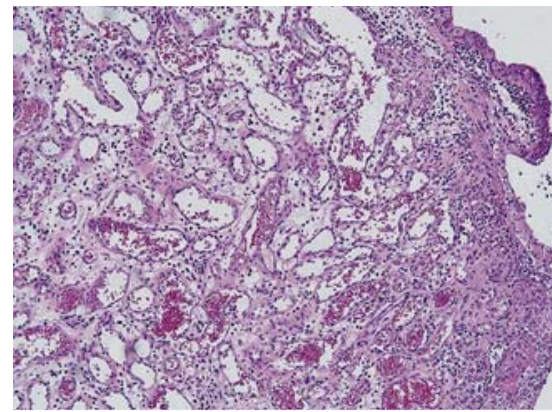

- Fig. 4 The lesion showed proliferation of capillary vessels with a rich component of inflammatory cells, edema, and sparse fibrosis, and no nuclear atypia or mitotic activity (hematoxylin and eosin, $\times 100$ ).

3 Pathology and Forensic Medicine Department, Faculty of Medicine of Ribeirão Preto, University of Sao Paulo, Ribeirão Preto, Brazil

\section{Corresponding author}

\section{Ricardo Stefano da Penha, MD}

Center for Gastrointestinal Endoscopy, Surgery and Anatomy Department, Faculty of Medicine of Ribeirão Preto, Bandeirantes Avenue 3900, Monte Alegre 14049-900, Ribeirão Preto, São Paulo, Brazil stefano@hcrp.usp.br

\section{References}

[1] Hayashi Y, Hosoe N, Takabayashi K et al. Clinical and endoscopic characteristics of pyogenic granuloma in the small intestine: a case series with literature review. Intern Med 2020; 59: 501-505

[2] Korc P, McHenry L. An uncommon cause of chronic upper GI bleeding. Gastrointest Endosc 2016; 84: 524
[3] Mandaliya R, Han S, Haddad N. Bleeding pyogenic granuloma of the ampulla of Vater: a rare cause of severe chronic anemia. Gastrointest Endosc 2019; 89: 1066-1067

[4] Tang S, Bhaijee F. Pyogenic granuloma of the ampulla of Vater. Video J Encycl GI Endosc 2014; 1: 622-624

[5] Camacho J, Pereira J, Arenas A. Hemangioma capilar como causa de colestasis extrahepática: reporte de caso. Gen 2012; 66 130-132

\section{Bibliography}

Endoscopy 2022; 54: E195-E196

DOI 10.1055/a-1480-6984

ISSN 0013-726X

published online 12.5.2021

(c) 2021. Thieme. All rights reserved.

Georg Thieme Verlag KG, Rüdigerstraße 14, 70469 Stuttgart, Germany

\section{ENDOSCOPY E-VIDEOS}

https://eref.thieme.de/e-videos

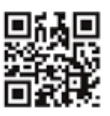

Endoscopy E-Videos is an open access online section, reporting on interesting cases and new techniques in gastroenterological endoscopy. All papers include a high quality video and all contributions are freely accessible online. Processing charges apply (currently EUR 375), discounts and wavers acc. to HINARI are available.

This section has its own submission website at https://mc.manuscriptcentral.com/e-videos 